PR-7

\title{
GREEN SYNTHESIS OF 2-AMINO-3-CYANO-4H-CHROMEN-4-YLPHOSPHONATES
}

\author{
G. Mohan, ${ }^{1,2}$ S. Murali, ${ }^{1}$ S. Santhisudha, ${ }^{1}$ C. Sridevi, ${ }^{3}$ \\ N. Bakthavatchala Reddy, ${ }^{4}$ G. V Zyryanov, ${ }^{4,5}$ C. Suresh Reddy ${ }^{1 *}$ \\ ${ }^{1}$ Department of Chemistry, Sri Venkateswara University, \\ Tirupati-517 502, Andhra Pradesh, India.
}

${ }^{2}$ DST PURSE Centre, Sri Venkateswara University, Tirupati-517 502, Andhra Pradesh, India.

${ }^{3}$ Department of Chemistry, SPW Degree and PG College,

Tirupati-517 502, Andhra Pradesh, India.

${ }^{4}$ Ural Federal University, Chemical Engineering Institute Yekaterinburg, 620002, Russian Fedaration.

${ }^{5}$ I. Ya. Postovskiy Institute of Organic Synthesis, Ural Division of the Russian Academy of Sciences, 22 S. Kovalevskoy St., 620219 Yekaterinburg, Russian Federation.

*Corresponding author e-mail: csrsvu@gmail.com

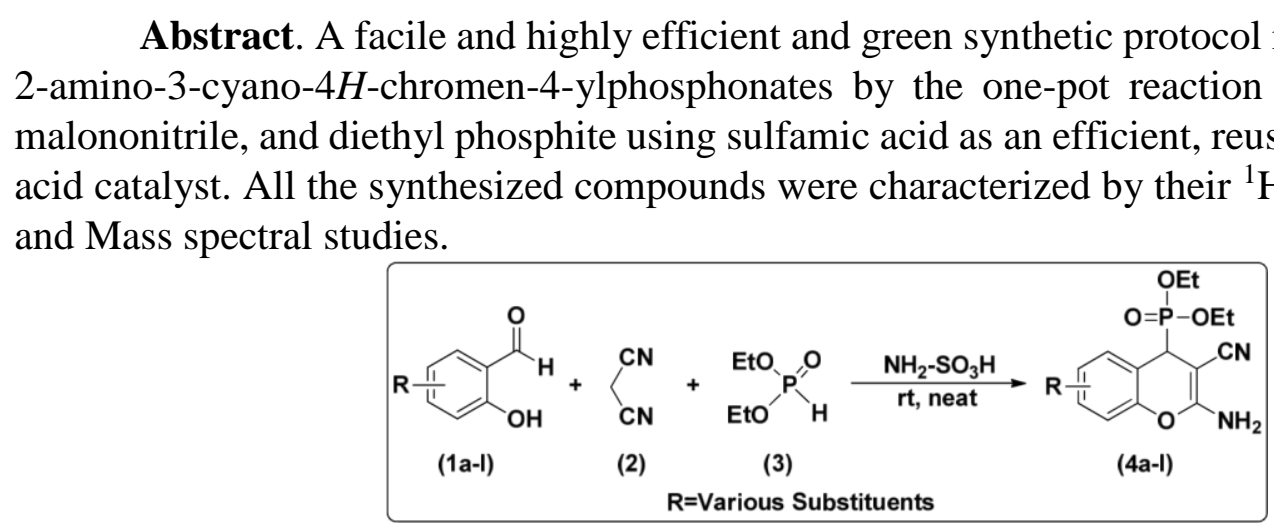

